the phenomenological literature if he seeks illumination on the (apparent) objections he has raised consulting in particular the works of Kurt Goldstein, Aron Gurwitsch, Maurice Merleau-Ponty and R. D. Laing. Suffice it now to say that his notion of "a phenomenological metaphysic" is fundamentally incoherent. It has been the perpetual endeavour of phenomenology to avoid (Husserl) or to dissolve (Heidegger) questions regarded in the philosophical tradition as "metaphysical". The ambition of both the founding fathers (Husserl and Heidegger) has been to recover, in their own striking but divergent ways, and in an absolutely original manner, the primordial experience of man's contact with the world.

\section{Hillfield Mansions \\ London NW3 4QR}

\section{Further reading}

SPIEgelberg, H. (1972) Phenomenology in Psychology and Psychiatry: A historical introduction. Evanston: Northwestern University Press.

- (1982) The Phenomenological Movement: A historical introduction. The Hague: Martinus Nijhoff.

Straus, E. W., Natanson, M. \& Ey, H. (1969) Psychiatry and Philosophy. Berlin and Heidelberg: Springer-Verlag.

\section{Fear of flying}

DeAR SIRS

I am writing to enquire whether there are practitioners working in the field of the treatment of fear of flying who would like to take part in an international study I am coordinating. The study was developed following presentation of my research results at several international conferences. The research examined the nature of fear of flying and the process of cognitive change during treatment which consisted of a standardised two session treatment programme, the second session being a return flight to Europe.

Contact has been made with doctors and psychologists working in various centres, and a standardised questionnaire developed which will enable international comparisons to be made on the different types of treatment, and their effectiveness, and add to the understanding of the process of cognitive change.

Clinicians are invited to participate in this study. Referrals are also being accepted for the study.

Please contact Elaine Iljon Foreman, Chartered Clinical Psychologist, at EIF Consulting Rooms, 21A Dean Road, London NW2 5 AB (telephone/fax 0814593428 , for further details).

I look forward to your reply.

Elaine IlJON Foreman

\title{
Psychiatric vignettes
}

The editors welcome vignettes of not more than 300 words. 'Tea with Alzheimer' by Henry R. Rollin
(Psychiatric Bulletin, September 1993, 17, 566) can be used as a model.

\section{Errata}

'Preparing for Mental Health Review Tribunals: reports and dilemmas' by B. Brockman (Psychiatric Bulletin, September 1993, 17, 544-547): the second reference should have read Langley, G.E.
'Counselling in Primary Care? Expectations, values and effectiveness' (Conference briefing, Psychiatric Bulletin, March 1993, 17, 169): the correct spelling of the author's name is Margreet Peutz. 